\title{
Governança do risco: uma proposta para lidar com riscos ambientais no nível local
}

\section{Risk Governance: A Proposal to Cope with Environmental Risks at Local Level}

\author{
Gabriela Marques DI GIULIO* \\ Lúcia da Costa FERREIRA**
}

\begin{abstract}
RESUMO
As mudanças ambientais e climáticas envolvem evidências frágeis e conflituosas sobre as explanações científicas quanto às consequências globais e locais, a eficiência das medidas adotadas para diminuir a vulnerabilidade e a eficácia das ações mitigadoras e adaptativas. Frente à complexidade e às incertezas científicas relacionadas a estes fenômenos ambientais e os riscos associados a eles - sentidos, sobretudo, no nível local -, neste trabalho é defendida a prática de um novo modelo de produção de conhecimento e de tomada de decisão, identificado como governança do risco. A adoção desse modelo parece ser especialmente útil no nível local, já que quanto mais envolvida estiver uma comunidade no processo decisório, maior será a possibilidade de induzir o público geral a agir individualmente/coletivamente para reduzir o risco e de envolvê-lo nas ações de mitigação/adaptação. Na tentativa de contribuir para esse debate, uma pesquisa empírica foi realizada em três cidades costeiras do Litoral Norte Paulista (São Sebastião, Caraguatatuba e Ubatuba), onde dois métodos participativos - grupos focais e workshop interativo - foram aplicados. Este artigo ${ }^{1}$ traz resultados referentes à aplicação desses métodos, buscando contribuir para o debate sobre governança do risco. Discute ainda a possibilidade de uso da ferramenta conhecida como cenário-workshop, cujo objetivo é facilitar a participação ativa dos diferentes stakeholders na discussão sobre o desenvolvimento sustentável das cidades e possíveis soluções técnicas.
\end{abstract}

Palavras-chave: governança do risco; mudanças climáticas e ambientais; Litoral Norte; métodos participativos.

\begin{abstract}
Environmental and climate change involve fragile and conflicting evidences about scientific explanations of global and local consequences, about efficiency of adopted measures to decrease the vulnerability,
\end{abstract}

\footnotetext{
" Doutora em Ambiente e Sociedade (UNICAMP). Professora do Departamento de Saúde Ambiental da Faculdade de Saúde Pública da Universidade de São Paulo (USP).E-mail: gabrieladigiulio@yahoo.com.br

"* Doutora em Ciências Sociais (UNICAMP). Pesquisadora do Núcleo de Estudos e Pesquisas Ambientais (NEPAM) da Universidade Estadual de Campinas (UNICAMP).E-mail: luciacf@unicamp.br

${ }^{1}$ Uma primeira versão deste texto foi apresentada no VI Encontro Nacional da Anppas, 2012, Belém.
} 
and about the efficacy of mitigating and adaptive actions. Considering the complexity and the scientific uncertainties related to these environmental phenomena and the risks associated to them, which has been felt at the local level in particular, in this paper we argue for a practice of a new model of knowledge production and decision-making, which is identified as risk governance. The adoption of this model is especially useful at the local level, since the more a community is engaged in the decision-making process, the greater is the possibility of inducing the general public to act individually/collectively to reduce risks and involve these individuals at the mitigating and adaptive actions. Drawing on an empirical research at three cities on the North São Paulo Coast (São Sebastião, Caraguatatuba and Ubatuba), we seek to contribute to this debate and present some results of two participatory methods - focus groups and interactive workshops. We also discuss the scenario-workshop method, a tool to facilitate the active participation of different stakeholders in the sustainable development of cities and possible technical solution debates.

Keywords: risk governance; environmental and climate change; North São Paulo Coast; participatory methods

\section{Introdução}

As mudanças ambientais e climáticas envolvem evidências frágeis e conflituosas sobre as explanações científicas quanto às consequências globais e locais, a eficiência das medidas adotadas para diminuir a vulnerabilidade e a eficácia das ações mitigadoras e adaptativas. Frente à complexidade e às incertezas científicas relacionadas a estes fenômenos ambientais e os riscos associados a eles - sentidos, sobretudo, no nível local -, pesquisadores, órgãos de governo e agências reguladoras começam a reconhecer a necessidade de colocar em prática um novo modelo de produção de conhecimento e tomada de decisão.

Esse modelo encontra respaldo no processo de governança do risco, termo que descreve um novo arranjo institucional no qual o processo decisório é coletivo, envolvendo atores governamentais e não governamentais. Jasanoff e Martello (2004) apontam que, no processo de governança ambiental, especialmente, as limitações da ciência (as incertezas e a ignorância), bem como o reconhecimento das dimensões sociais na produção do conhecimento, constituem justificativas fortes no que se refere ao espaço e à atenção que merecem as perspectivas locais e os conhecimentos tradicionais.

O termo governança do risco é definido e adotado neste artigo partindo-se dos argumentos propostos por Renn (2008): (a) requer o envolvimento de representantes dos diferentes grupos sociais que estão na arena; (b) o empoderamento de todos os atores na participação e construção do discurso; (c) o processo de construção conjunta do problema a ser enfrentado; (d) a proposição de uma compreensão comum da magnitude do risco, das opções de gerenciamento e a inclusão de uma pluralidade de opções que representem os diferentes interesses e valores de todas as partes envolvidas; (e) a condução de um fórum para o processo decisório; e (f) a possibilidade de estabelecer uma conexão entre aqueles que participam da decisão e aqueles que a implementam (no nível político).

A necessidade da prática da governança do risco para lidar com riscos associados às mudanças climáticas e ambientais (particularmente aqueles associados aos desastres naturais e aos eventos climáticos extremos) parece ser bastante clara no nível local, já que, quanto mais envolvida estiver uma comunidade no processo decisório, maior é a possibilidade de induzir o público geral a agir individual ou coletivamente para reduzir o risco (DAVIS, 1996; KASPERSON e PALMLUND, 2005) e de envolvê-lo nas ações de mitigação e adaptação.

A proposta, claro, é desafiadora e inclui importantes questões: quem fala pela comunidade? Que grupos podem contribuir para o processo decisório? Que mecanismos e estratégias devem ser usados para incluir a participação dos stakeholders e do público no processo de tomada de decisão? Que fatores são necessários para garantir uma participação pública de sucesso?

$\mathrm{Na}$ tentativa de iluminar essas questões e contribuir para o debate sobre governança do risco, uma pesquisa empírica foi realizada em três cidades costeiras do Litoral 
Norte Paulista: São Sebastião, Caraguatatuba e Ubatuba ${ }^{2}$. Nestas cidades, a exemplo do que acontece em outros municípios brasileiros, há problemas de urbanização que, em um contexto de aumento da intensidade e frequência de eventos extremos, podem antecipar a tendência de aumento expressivo de situações de vulnerabilidade socioambiental (HOGAN et al., 2001; CARMO e SILVA, 2009). Cabe lembrar ainda que a implantação de novos projetos ou a expansão dos já existentes, como implantação de obras viárias, oleodutos e gasodutos, linhas de transmissão ou expansão urbana, introduz ou intensifica fatores perturbadores do já tenso equilíbrio na região.

A partir de pesquisas de campo, com realização de observações, entrevistas e grupos focais com gestores e técnicos responsáveis pela avaliação e gerenciamento de riscos nestas cidades, com lideranças de bairros e jovens estudantes, é possível apontar alguns elementos que têm caracterizado como os riscos e problemas associados a desastres naturais e eventos climáticos extremos têm sido enfrentados na região, como: o atraso ou a ausência de ações institucionais; a falta de confiança do público afetado nas agências e órgãos responsáveis pela regulação e gerenciamento dos riscos; a ausência de um plano para engajar o público no processo de tomada de decisão (o envolvimento público é limitado ao acesso à informação e à participação em alguns exercícios de consulta); e um processo decisório ainda excessivamente centralizado.

Considerando essas características e a necessidade de que nessas cidades costeiras seja colocado em prática um processo de tomada de decisão participativo para lidar com os riscos associados às mudanças climáticas e ambientais no nível local, é discutida a aplicação de dois métodos participativos - grupos focais e workshop interativo - e a possibilidade de uso da ferramenta conhecida como cenário-workshop (European Awareness Scenario Workshops - EASW), cujo objetivo é facilitar a participação ativa dos diferentes stakeholders na discussão sobre o desenvolvimento sustentável das cidades e possíveis soluções técnicas (GNAIGER e SCHROFFEREGGER, 2008).

\section{Mudanças climáticas e ambientais e seus riscos}

As zonas costeiras são as áreas de maior risco no mundo e serão as porções mais afetadas pelas mudanças ambientais globais (KRON, 2008). Entre os diversos efeitos dessas mudanças globais, estão aqueles associados ao aumento do nível médio dos oceanos e a maior frequência e intensidade de eventos climáticos extremos, muitas vezes implicando variações dos níveis das marés, riscos de inundações, enchentes, alagamentos e deslizamentos (IPCC, 2007).

É nas zonas costeiras de baixa altitude (Low Elevation Coastal Zones), áreas contíguas ao longo da costa com menos de dez metros acima do nível do mar, que residem cerca de $10 \%$ da população mundial e $13 \%$ da população urbana mundial. Os assentamentos situados em planícies costeiras são especialmente vulneráveis aos riscos das mudanças climáticas devido às suas áreas densamente povoadas e urbanizadas (McGRANAHAN, BALK e ANDERSON, 2007).

No Brasil, dados do Censo 2007 (IBGE, 2007) indicavam que aproximadamente 43 milhões de habitantes ( $22,5 \%$ da população total) residiam na zona costeira, na qual se localizam 16 das 28 regiões metropolitanas brasileiras. Carmo e Silva (2009) já apontavam que, nesse mesmo ano dos dados divulgados pelo IBGE, 70\% da população que residia em municípios da zona costeira vivia em municípios com sedes em altitudes inferiores a 20 metros; $16,77 \%$ em cidades com altitudes entre zero e dois metros.

Nestas cidades, a exemplo do que acontece em outras áreas brasileiras, há problemas de urbanização, como ocupações irregulares em encostas ou nas margens dos corpos de água, precariedade de abastecimento de água potável e de saneamento básico, entre outros elementos indicativos de inadequação e de má distribuição dos serviços e da infraestrutura no meio urbano (CARMO e SILVA, 2009). Em um contexto de cenários de aumento da intensidade e frequência de eventos extremos, alguns

\footnotetext{
${ }^{2}$ Esta pesquisa, desenvolvida no âmbito de um estágio de pós-doutoramento, buscou identificar e analisar demandas e desafios do processo de enfrentamento de situações de risco nestas cidades do litoral norte de São Paulo e compreender como os indivíduos respondem ao problema das mudanças climáticas e ambientais, aos possíveis conflitos que poderão ser gerados com os novos empreendimentos instalados na região (no contexto dessas mudanças) e às informações disponíveis sobre os riscos.
} 
autores já antecipam a tendência de aumento expressivo de situações de vulnerabilidade socioambiental nas áreas litorâneas (HOGAN et al., 2001; CARMO e SILVA, 2009).

O Litoral Norte Paulista é uma dessas áreas potencialmente vulneráveis e objeto de estudo do presente trabalho. Além de conciliar os interesses dos veranistas, da população residente que busca emprego e uma melhor qualidade de vida e dos ambientalistas que defendem o patrimônio natural, a região precisará lidar com empreendimentos de grande potencial para provocar mudanças na vocação econômica local, como as obras de ampliação na rodovia Tamoios, expansão do porto de São Sebastião e obras de exploração de gás no Complexo Mexilhão na Bacia de Santos, com a instalação da Unidade de Tratamento de Gás de Caraguatatuba - a UTGCA (VIGLIO, 2012; FERREIRA et al., 2012).

No contexto de mudanças climáticas e ambientais, com o aumento da intensidade e frequência de eventos extremos, e considerando os estudos realizados na região e a análise de narrativas colhidas em entrevistas e grupos focais, é possível apontar alguns dos riscos potenciais aos quais os moradores do Litoral Norte podem estar expostos. Entre esses riscos, destacam-se: (a) mudanças na intensidade e frequência de chuvas (com períodos de chuva de curta duração, mas bastante intensos), facilitando a ocorrência de deslizamentos, enchentes e fortes vendavais, com queda de árvores e destelhamentos de residências; (b) aumento na temperatura, trazendo riscos à saúde, desconforto e a proliferação de novas doenças; (c) elevação do nível do mar. Além desses riscos, as narrativas colhidas também sugerem os riscos associados às atividades tecnológicas, sobretudo as ligadas à extração e ao transporte de petróleo e gás natural.

Todavia, é preciso reconhecer que esses riscos potenciais, quando olhados no contexto das mudanças climáticas e ambientais e dentro de uma perspectiva construtivista ${ }^{3}$, apresentam algumas características semelhantes, reconhecidas por Beck já na sua obra Risk Society (1992): esses riscos são muitas vezes invisíveis, incalculáveis e impossíveis de serem compensados e controlados; suas causas e consequências não são compreendidas completamente e eles apresentam consequências potencialmente catastróficas (BECK, 1992).

\section{Governança dos riscos}

Dadas as características comuns desses riscos associados às mudanças climáticas e ambientais, o debate sobre as possibilidades e os desafios da prática da governança do risco como uma estratégia de enfrentamento desses problemas tem ganhado notoriedade recentemente. Esse debate considera, particularmente, que (a) as percepções de risco individuais influenciam as condutas individuais e coletivas e as ações mitigadoras e adaptativas e que (ii) o enfrentamento de situações de riscos associadas a essas mudanças, por envolverem riscos complexos cujas relações de causas e efeitos são bastante complexas e difíceis de serem identificadas e mensuradas, requer a prática de um processo decisório aberto e participativo.

Nesta nova estratégia, o diálogo sobre a qualidade e a formulação de políticas para enfrentar problemas e riscos é considerado de fundamental importância e é estendido a todos os afetados pela questão. Como observam os autores Funtowicz e Ravetz (1997, p. 229), em situações de riscos, "o conhecimento das condições locais ajuda a determinar que dados são consistentes e relevantes e também a definir os problemas que devem ser alvo das políticas". O acesso a tais informações só é possível quando há o reconhecimento de que aquelas pessoas que vivenciam o risco também possuem seu próprio conhecimento sobre os problemas que as atingem e que, portanto, devem participar do diálogo e do processo de tomada de decisão.

A ampliação e o reconhecimento do debate sobre participação pública no processo decisório em situações de risco são resultados de diversas experiências empíricas que têm evidenciado, como reconhece Freitas (2000), a necessidade de considerar que o risco se vivencia no interior de cenários, onde as falas, silêncios, expressões e

\footnotetext{
${ }^{3}$ A perspectiva construtivista do risco não nega a existência de uma realidade objetiva nem o poder causal independente dos fenômenos naturais, mas foca em como os riscos são definidos e que significados recebem de diversos grupos e atores sociais (GUIVANT, 1998, 2002).
} 
segredos são objetos de um conhecimento coletivamente elaborado. Este conhecimento coletivo é elaborado em contextos sociais específicos e complexos que formam unidades pertinentes na compreensão de como se articulam os comportamentos individuais e a construção coletiva da percepção de riscos, bem como diversos tipos de clivagens e de conflitos que surgem no interior dessa construção comum (FREITAS, 2000).

No conceito de governança do risco, está implícita a ideia de um processo decisório democrático e participativo relacionado ao gerenciamento do risco, entendendo participação como o compartilhamento do poder decisório do Estado em relação às questões relativas ao interesse público (DAGNINO, OLVERA e PANFICHI, 2006) e como condição necessária para assegurar que as instituições governamentais atuem de forma responsável perante seus cidadãos, criando possibilidades para que indivíduos e grupos influenciem as decisões que os afetam (promovendo assim competência e capacidade para isso) e contribuindo para a estabilidade do sistema democrático (ASHFORD e REST, 1999).

Governança, como argumentam os autores Jasanoff e Martello (2004), significa regras, processos e comportamentos que afetam a forma como os poderes são exercidos, sobretudo no que tange à abertura, participação, eficiência, coerência e responsabilidade presentes no processo decisório.

Guimarães e Martin (2001) sustentam que governança é um conceito endereçado a capturar situações onde o que está em jogo é a coordenação entre atores interdependentes, de forma a lidar com as questões da ação coletiva e da cooperação. O conceito contém um pressuposto substantivo de que a coordenação de um complexo de atividades, públicas e/ou privadas, se constitui no modo mais fácil de assegurar a execução com eficiência. Para os autores, no conceito de governança há alguns elementos convergentes de análise: i) em conceber a todos os que participam do processo de tomada e implementação de decisões como partes corresponsáveis; ii) em conceber o processo de produção dos recursos - sejam eles financeiros, organizacionais, humanos ou informacionais - como resultado de parcerias horizontais, intra e interorganizacionais; iii) em valorizar as estruturas decentralizadas e participativas, que integram os que tomam as decisões, os que as im- plementam e os que as acompanham (e/ou avaliam) em circuitos unificados por um processo de aprendizagem organizacionalmente dirigida (GUIMARÃES e MARTIN, 2001).

Gaudin (2001) reconhece que as boas intenções que cercam a governança, muitas vezes, contrastam com o que revela a análise das práticas encorajadas para fomentar a participação pública no processo decisório.

As condições de possibilidade [para que de fato aconteça o envolvimento do público] não parecem suficientemente aprofundadas, e isto continuará a ocorrer enquanto não for claramente estabelecida a relação entre o que se coloca nos fóruns de debate (que mobilizam efetivamente os cidadãos ou a opinião pública) e o que está em jogo nas arenas de tomada de decisão (frequentemente fechadas e funcionais) onde a ação propriamente dita é negociada (JOBERT, 1992). Por enquanto, o impasse democrático da governança ainda parece difícil de ser superado (GAUDIN, 2001, s/p).

O termo governança do risco é usado neste trabalho partindo-se das definições propostas por Renn (2008). Assim, governança de risco é um processo que envolve representantes de todos os grupos sociais (stakeholders, público diretamente afetado, público observador, autoridades, agências reguladoras) e requer que esses atores possam participar ativamente e de forma construtiva no discurso para que consigam chegar a uma compreensão comum a respeito da magnitude do risco e sobre quais as formas efetivas para gerenciá-lo.

É a partir desse entendimento que se defende neste trabalho que, em situações de risco associadas às mudanças climáticas e ambientais, ou potencializadas por esses fenômenos, a prática de um processo decisório mais aberto e participativo, que inclua as percepções, necessidades e interesses das comunidades afetadas, é relevante. As justificativas estão embasadas na premissa de que as decisões regulatórias, por sua complexidade, ambivalência e incertezas, não podem ser baseadas apenas no conhecimento técnico, elas devem incluir a participação dos stakeholders e envolver o público.

A existência de espaço compartilhado, que vai além dos limites preestabelecidos acerca dos papéis desempenhados por cada ator envolvido e reconhece a impor- 
tância do público no processo decisório (CORNWALL, 2008), e a relação de confiança ${ }^{4}$ são defendidas neste artigo como elementos fundamentais na governança do risco. Considera-se também que o contexto político e social tem peso neste processo. Seguindo o argumento de Renn (2008), esse contexto sócio-político está sustentado por quatro pilares: capacidade organizacional, cultura política e regulatória, rede de atores e clima social/cultura do risco.

A capacidade organizacional se refere a uma organização específica ou a um grupo de organizações responsáveis por lidar com os riscos no âmbito individual, empresarial, de governo local ou nacional, internacional ou em uma combinação de níveis. No caso da cultura política e regulatória, é preciso considerar que um mesmo risco pode ser processado diferentemente e estar sujeito a diversas decisões de gerenciamento, dependendo de alguns fatores como cultura nacional, tradição política e normas sociais. Em alguns ambientes, uma abordagem top-down (de cima para baixo) prevalecerá; em outros, a abordagem adotada será de uma governança horizontal. A rede de atores envolve todos aqueles que estão em jogo em uma situação de risco e que serão impactados pelas possíveis consequências. Estão envolvidos, assim, governos locais, regionais e nacionais; diferentes setores industriais; agências de regulação; organizações não governamentais; a mídia e o público em geral. Compreender quem são os atores presentes no nível da governança é importante para caracterizar o risco, avaliá-lo, julgar a aceitabilidade e tolerância, comunicá-lo e tomar as decisões sobre como gerenciá-lo.

Como observa Renn (2008), compreender o clima social e a cultura de risco é importante para julgar o nível de preparo para as mudanças necessárias e para as decisões que serão tomadas. Em geral, os fatores que compreendem o clima social e a cultura de risco têm impactos nas visões sobre justiça, conveniência e praticabilidade de uma decisão tomada.
A cultura nacional, as tradições políticas e as normas sociais influenciam os mecanismos e as instituições para integrar conhecimento e expertise nas arenas políticas. A política cultural ou o regime regulatório vigente em determinada sociedade é, na visão de Renn (2008), aspecto fundamental na prática da governança de risco.

\section{A construção de uma proposta}

A proposta de governança do risco, que inclui um processo participativo para o enfrentamento de situações de riscos associados às mudanças climáticas ou ambientais, ou potencializadas por esses fenômenos, passa pela necessidade de identificar como os indivíduos - sobretudo aqueles que estão potencialmente expostos e vivenciam o risco e aqueles que precisam dar uma resposta urgente a estas situações - percebem esses riscos.

Para isso, uma metodologia qualitativa foi adotada na pesquisa conduzida pelas autoras, com um levantamento de campo exploratório utilizando entrevistas com diferentes atores sociais e a realização de grupos focais.

O grupo focal, na condução da pesquisa, foi entendido e adotado como um método qualitativo para aferir as percepções de risco e investigar as estratégias de comunicação e enfrentamento dos riscos e problemas e, ao mesmo tempo, um método participativo para possibilitar intercâmbios de experiências e conhecimentos sobre as situações de risco potencializadas pelas mudanças climáticas e ambientais com stakeholders, público diretamente afetado e autoridades locais.

Vale ressaltar que o grupo focal, uma forma de pesquisa qualitativa, é baseado em entrevistas grupais, cujo objetivo é propiciar um entendimento de como se formam e se diferem as percepções, opiniões e atitudes acerca de um fato, produto ou serviço (KRUEGER, 1994; MORGAN, 1988, 1998). Esse método permite extrair a percepção dos participantes sobre o tópico em

\footnotetext{
${ }^{4}$ Renn e Levine (1991), ao refletirem sobre a importância da confiança no processo comunicativo entre diferentes atores sociais, sustentam que confiança refere-se à expectativa generalizada de que a mensagem transmitida é verdadeira e que aquele que a comunica demonstra competência e honestidade para isso. Parker et al. (2008) sugerem três fatores importantes na construção da confiança pessoal: a confiança tem de ser construída como uma relação de duas vias, tem de ser baseada na honestidade, confiabilidade e regularidade e vai além de um aspecto racional, já que há um aspecto emocional envolvido. Confiança, assim, é composta tanto por elementos racionais (cognitivos) como emocionais (afetivos).
} 
questão. Considerando que as percepções, opiniões e atitudes são socialmente construídas, o método de grupo focal possibilita extrair mais facilmente a expressão dos indivíduos participantes, já que no processo de interação os comentários colocados por uns podem estimular e gerar opiniões de outros participantes sobre o assunto debatido (KRUEGER, 1994).

Foram realizados três grupos focais com gestores e técnicos que atuam direta e indiretamente em avaliação e gestão de riscos nos três municípios abordados na pesquisa, incluindo representantes das Secretarias de Meio Ambiente, Planejamento e Educação, Defesa Civil e do Parque Estadual da Serra do Mar, entre outros; dois grupos com lideranças de bairros considerados como áreas de riscos nos municípios de São Sebastião e Caraguatatuba; e um com jovens de 12 a 17 anos de idade, estudantes e moradores de um bairro considerado área de risco e de proteção ambiental, pertencente ao município de Caraguatatuba ${ }^{5}$. Todos os participantes assinaram o termo de consentimento, dando consentimento livre e esclarecido para participar como voluntários do projeto de pesquisa, estando cientes, assim, dos objetivos e procedimentos do estudo. Para a participação desses encontros, gestores e técnicos foram contatados anteriormente por meio de e-mails e de telefonemas, nos quais foram feitos oficialmente os convites e confirmadas as presenças. No caso dos moradores e jovens, os contatos prévios foram feitos pelas pesquisadoras, por uma liderança local e por uma educadora ambiental (e moradora de um dos bairros).

Algumas questões norteadoras foram consideradas na realização desses grupos focais: como os indivíduos respondem ao problema das mudanças climáticas e ambientais, à realização de pesquisa, aos novos empreendimentos e às informações disponíveis sobre os riscos? Que fatores interferem nestas respostas? Quais eventos de risco são citados pelos participantes no desenvolvimento das suas respostas? Como os indivíduos pensam e percebem sua capacidade de proteção, adaptação e reação frente a esses riscos? Como se engajam e participam do debate e do processo decisório?

A proposta desse processo participativo também passa pela realização de workshops interativos, que reúnem pesquisadores, tomadores de decisão (gestores e técnicos), lideranças de bairros e outros representantes da sociedade civil com o intuito de trocar experiências e conhecimentos sobre as situações de risco que têm sido estudadas e que podem ser potencializadas pelas mudanças climáticas e ambientais. O objetivo maior desses workshops é promover uma revisão conjunta dos problemas investigados, do desenho da pesquisa, dos resultados que têm sido obtidos, da forma de coleta/ análise/divulgação das informações e da influência do conhecimento obtido nas decisões coletivas e individuais.

Com a ideia de promover uma maior aproximação entre os atores sociais envolvidos na arena de risco e possibilitar um intercâmbio de experiências e conhecimentos sobre riscos associados às mudanças climáticas no litoral norte paulista, conflitos provocados pelos impactos da expansão urbana recente sobre a cobertura florestal, diferentes estudos que têm sido conduzidos e demandas identificadas para a região, uma experiência de um workshop interativo foi organizada no âmbito do Projeto Temático, ao qual o estudo conduzido pelas autoras é vinculado.

Na perspectiva de ser um exercício participativo permitindo compreender também a influência do conhecimento científico gerado nas decisões locais tomadas, o workshop contou com a participação de pesquisadores do Projeto Temático e de stakeholders locais (gestores e técnicos do Litoral Norte Paulista), que puderam participar efetivamente do evento no primeiro dia, uma vez que

\footnotetext{
${ }^{5}$ Entendendo que os estudos sociológicos e culturais sobre percepção de risco enfocam os estímulos sociais e culturais que evocam certos padrões ou atributos específicos associados a diferentes tipos de risco (RENN, 2008) e, assim, tendem a considerar valores culturais, visões de mundo, relações institucionais, julgamentos estéticos, variáveis contextuais, imagens semânticas, valores, efeitos da comunicação (incluindo a mídia), confiança nas organizações e instituições, além de considerações qualitativas (como temor, potencial catastrófico, caráter controlável dos acontecimentos, equidade, incerteza, o risco para as gerações futuras) e a própria questão da identidade (uma vez que o ambiente onde os indivíduos nasceram e cresceram é de fundamental importância para a construção e continuidade de suas identidades), foi proposta a realização de um grupo focal com jovens de 12 a 17 anos de idade, tendo em vista possibilidades de identificar e confrontar semelhanças e diferenças com as narrativas obtidas com os outros grupos com relação às compreensões sobre causas e efeitos das mudanças climáticas, às percepções sobre as questões ambientais, às conexões dos assuntos debatidos nos grupos focais com suas vidas cotidianas, formas de engajamento e participação no processo decisório e expectativas de mudanças.
} 
apresentaram dados de estudos que têm embasado suas decisões, expuseram suas percepções sobre os problemas da região e sobre os riscos ambientais e tecnológicos e expressaram suas demandas e necessidades de pesquisa.

Todavia, é preciso ressaltar que, mesmo com a proposta de ser um workshop participativo e aberto no primeiro dia, apenas cinco gestores e técnicos participaram do evento, representando CETESB, IBAMA, Defesa Civil de Caraguatatuba e Núcleo Caraguatatuba do Parque Estadual da Serra do Mar. A pouca adesão dos outros convidados (que representavam as secretarias de meio ambiente e as defesas civis dos quatro municípios do Litoral Norte, a Vigilância Epidemiológica Regional, Comitê de Bacia Hidrográfica e o Conselho Municipal de Saúde de Caraguatatuba), apesar das suas justificativas de compromissos anteriormente assumidos, sinaliza as dificuldades em promover um laboratório participativo como este.

Essas dificuldades passam também por aspectos relacionados à participação, mobilização e engajamento do público (neste caso, de um público específico) em processos decisórios, em geral, e no processo de pesquisa, em particular. Como apontam Wilsdom et al. (2005), o engajamento do público é uma forma de manter e renovar o contrato social que suporta a Ciência, já que a maior inserção e a participação do público nas decisões tomadas promovem a discussão dos valores públicos da ciência e encorajam o diálogo entre os grupos sociais, que vai além das proposições competitivas, mas alcança uma discussão de visões e finalidades. Além disso, o envolvimento do público - nas trajetórias de pesquisas que ainda se encontram abertas e não determinadas - pode ser o começo para um processo de deliberação e de avaliação social, que proporciona o diálogo entre cientistas, stakeholders e público leigo em todos os estágios do processo de pesquisa e desenvolvimento.

De toda forma, mesmo considerando a pouca adesão dos stakeholders locais, é possível afirmar que as atividades propostas e cumpridas durante o workshop permitiram o cumprimento dos objetivos do evento.

Estes dois métodos (grupos focais e workshops interativos), aplicados no estudo, tiveram também o objetivo de facilitar e melhorar o diálogo entre quem produz conhecimento científico e aqueles que usam/ consomem este conhecimento para tomar decisões individuais e coletivas. Esses métodos ainda são vistos como parte das estratégias de uma proposta de comunicação de risco participativa. Essa proposta compreende que as ações de comunicação entre os diferentes grupos sociais envolvidos na arena do risco não estão limitadas ao modelo do déficit de conhecimento - que entende que o público leigo é ignorante sobre ciência ambiental e saúde, irracional nas suas respostas e, portanto, deve ser melhor informado e convertido em uma visão mais objetiva (OWENS, 2000). Ao contrário, essas ações promovem uma comunicação de mão dupla, sensível às necessidades da comunidade afetada, a integração do público no processo de gerenciamento do risco e, principalmente, o estabelecimento de uma relação de confiança entre os atores.

Em geral, os resultados obtidos com a aplicação desses métodos sugerem que o processo de enfrentamento dos problemas associados às situações de risco nestas localidades estudadas ainda é caracterizado pelo atraso ou pela ausência de ações institucionais; falta de confiança do público afetado nas agências e órgãos responsáveis pela regulação e gerenciamento dos riscos; ausência de um plano para engajar o público no processo decisório (o envolvimento público ainda é limitado ao acesso à informação e à participação em alguns exercícios de consulta); e um processo decisório ainda excessivamente centralizado.

Apontam também, por parte dos gestores, técnicos e moradores, duas limitações importantes que estes grupos têm para agir e tomar decisões em situações de risco: ausência de informação técnica e científica sobre mudanças ambientais e climáticas e dificuldade de usar a informação disponível nas suas decisões (individuais e coletivas). Essa dificuldade está associada, particularmente, às controvérsias relacionadas a causas e efeitos das mudanças climáticas e ambientais, o que torna, por exemplo, a adoção e a legitimação das medidas ambientais e políticas mais difíceis. Em alguns casos, está relacionada também à forma como as informações são divulgadas. Muitas vezes, os resultados de estudos sobre riscos associados às mudanças climáticas e ambientais, eventos extremos e desastres naturais, quando chegam às mãos de gestores, técnicos e de moradores, são relatados em uma linguagem acadêmica, dificultando a compreensão das informações. 
Os participantes dos grupos focais apontaram que há dificuldades no diálogo com outros grupos sociais (sobretudo com pesquisadores e técnicos), ausência de informação sobre resultados de pesquisas (o acesso aos resultados de estudos desenvolvidos na região ainda é falho) e uma necessidade urgente de melhorar a articulação entre a academia, setor público e comunidade de forma a garantir uma melhor divulgação de resultados e para que as políticas públicas sejam embasadas em conhecimento científico.

As narrativas colhidas sugerem ainda que o governo local tem dificuldade em usar a informação científica para responder aos problemas. Essa dificuldade está associada à ausência de recursos econômicos para implementar ações efetivas e/ou à ausência de interesse político para implementar soluções.

Esses resultados levam à discussão sobre a adoção de outro método participativo de produção de conhecimento e tomada de decisão. O método cenário-workshop (European Awareness Scenario Workshops - EASW, em inglês) tem o objetivo de facilitar a participação ativa dos diferentes stakeholders na discussão sobre o desenvolvimento sustentável das cidades e possíveis soluções técnicas (GNAIGER e SCHROFFEREGGER, 2008).

A proposta é envolver esses atores, por meio de um ou dois dias de reuniões e trabalhos intensos, no planejamento e no processo de tomada de decisão, motivados, sobretudo, a discutir e propor soluções realistas que possam ser encontradas para os problemas urbanos. Durante esse tempo, os participantes são chamados a pensar e buscar respostas para duas questões-chave: como deve ser mudado o comportamento para conseguirmos uma vida sustentável e em que medida uma solução de base tecnológica deve ser considerada? Quem é responsável pela solução dos problemas - os moradores, as autoridades locais ou os dois juntos? (GNAIGER e SCHROFFEREGGER, 2008).

A aplicação dessa ferramenta como uma estratégia inovadora de participação pública e como uma metodologia participativa importante para a prática da governança do risco é prevista em estudos futuros das autoras, verificando, assim, sua aplicabilidade, vantagens, limitações e impactos.

\section{Considerações finais}

O enfrentamento dos problemas e riscos associados às mudanças climáticas e ambientais, particularmente relacionados a desastres naturais e eventos climáticos extremos, demanda ações intra e intersetoriais e abordagens interdisciplinares que incluam comunicação de risco participativa, articulação, cooperação e integração entre os diferentes grupos sociais envolvidos (DI GIULIO, 2012).

A proposta deste artigo foi fazer uma reflexão sobre essas demandas a partir de um debate sobre governança do risco e de métodos participativos que foram pensados e aplicados nas cidades do litoral norte, contempladas no estudo das autoras.

A aplicação desses métodos participativos (grupos focais e workshops interativos) busca não apenas facilitar e melhorar o diálogo entre quem produz conhecimento científico e aqueles que usam/consomem este conhecimento para tomar decisões individuais e coletivas, mas também constitui um passo importante na discussão sobre governança do risco e sobre como a opção por determinadas ações está relacionada à capacidade organizacional, cultura política e regulatória, rede de atores, cultura nacional, tradições políticas e normas sociais vigentes dentro de uma sociedade. Esses elementos influenciam não apenas os mecanismos e as instituições para integrar conhecimentos (leigo e científico) nas arenas políticas, como também influenciam a existência de espaços públicos compartilhados que tenham impacto na definição da agenda pública, na vigilância das autoridades e na defesa de direitos.

No Brasil, é possível afirmar - ainda que com algumas importantes exceções - que as tentativas de envolvimento público são limitadas ao acesso a informações e à consulta, também limitada, já que os stakeholders da economia, ciência e política, em geral, definem previamente os assuntos nos quais as opiniões do público diretamente afetado são solicitadas.

A participação popular no processo decisório sobre riscos tende a envolver cobrança de medidas de controle e busca de esclarecimento quanto aos efeitos e cuidados que o sistema oferece para garantir o bem-estar dos indivíduos, como mostram, por exemplo, os estudos de Freitas (2004), 
Ferreira (2006) e Di Giulio (2012). O público diretamente afetado, aquele que vivencia de fato o risco, participa do processo apenas com pressão política esclarecida, mas quase nunca como formulador de propostas.

$\mathrm{Na}$ tentativa de facilitar que o processo decisório para lidar com os riscos e problemas associados às mudanças climáticas e ambientais, desastres naturais e eventos climáticos extremos seja de fato mais participativo (em outras palavras, que a governança de risco seja uma prática no enfrentamento desses problemas no litoral norte), as autoras propõem, além da adoção desses métodos, a adoção da ferramenta conhecida como cenário-workshop. Relatos e análises da aplicação do cenário-workshop têm mostrado que essa ferramenta

\section{Referências}

ASHFORD, N. A.; REST, K. M. Public participation in contaminated communities. Center for Technology, Policy and Industrial Development, Massachusetts Institute of Technology, Cambridge, Massachusetts, 1999. Disponível em: <http:// web.mit.edu/ctpid/www/t//TL-pub-PPCC.html\#ab>. Acesso em: ago. 2008.

BECK, U. Risk Society. Towards a New Modernity. London: Sage Publications, 1992.

CARMO, R. L.; SILVA, C. A. M. População em zonas costeiras e mudanças climáticas: redistribuição espacial e riscos. In: HOGAN, D. J; MARANDOLA Jr., E. J. (Orgs.). População e mudança climática: dimensões humanas das mudanças ambientais globais. Campinas: Núcleo de Estudos de População (NEPO/Unicamp); Brasília: UNFPA, 2009. p. 137-157.

CORNWALL, A. Democratizing engagement: What the UK can learn from international experience. London: DEMOS, 2008.

DAGNINO, E.; OLVERA, A. J.; PANFICHI, A. Para uma outra leitura da disputa pela construção democrática na América Latina. In: (Orgs.). A disputa pela construção democrática na América Latina. São Paulo: Paz e Terra, 2006. p. 13-91.

DAVIS, S. H. Public Involvement in Environmental Decision Making - Some Reflections on the Western European Experience. In: Social Policy e Resettlement Division Environment Department. Washington DC: The Work Bank, 1996. é útil para sensibilizar as pessoas para os problemas futuros, prover informação, identificar responsabilidades e prioridades, discutir as diferenças e semelhanças dos problemas e soluções a partir da percepção dos diferentes grupos de participantes.

\section{Agradecimentos}

As autoras agradecem o apoio financeiro da FAPESP (Processos 2008/58159-7, 2010/51849-8, 2012/02125-2), aos comentários e sugestões dos pareceristas e a todos os participantes dos grupos focais realizados no Litoral Norte Paulista.
DI GIULIO, G. M. Risco, ambiente e saúde: um debate sobre comunicação e governança do risco em áreas contaminadas. São Paulo: Annablume, 2012. 390 p.

FERREIRA, L. C. Os fantasmas do Vale: conflitos em torno do desastre ambiental em Cubatão. Política e Trabalho, v. 23, n. 25, p. 165-188, 2006.

; JOLY, C.; CARMO, R. L. Urban Growth, Vulnerability and Adaptation: Social and Ecological Dimensions of Climate Change on the Coast of São Paulo. Relatório Cientifico Anual, julho de 2011 a agosto de 2012. São Paulo, 2012.

FREITAS, C. M. A contribuição dos estudos de percepção de riscos na avaliação e no gerenciamento de riscos relacionados aos resíduos perigosos. In: SISINNO, C. L. S.; OLIVEIRA, R. M. (Org.). Resíduos sólidos, ambiente e saúde: uma visão multidisciplinar. Rio de Janeiro: Fiocruz, 2000. p. 111-128.

FREITAS, C. U. Vigilância de população exposta a chumbo no municipio de Bauru - São Paulo: investigação de fatores de exposição e avaliação da dinâmica institucional. São Paulo, Tese (Doutorado) - Faculdade de Saúde Pública, Universidade de São Paulo, 2004.

FUNTOWICZ, S.; RAVETZ, J. 1997. Ciência pós-normal e comunidades ampliadas de pares face aos desafios ambientais. Hist. Cienc. Saúde-Manguinhos, Rio de Janeiro, v. 4, n. 2, 1997.

GAUDIN, J. A governança moderna, ontem e hoje: alguns esclarecimentos a partir das políticas públicas francesas. In: 
CURSO DE GESTÃO URBANA E DE CIDADES, 3., 2001. Belo Horizonte: EG/FJP, WBI. Anais.

GNAIGER, A.; SCHROFFEREGGER, G. Tool-kit scenario. 2008. Disponível em: <http://www.uibk.ac.at/fbi/download/ fbibuchweb1.pdf $>$. Acesso em: set. 2012.

GUIVANT, J. S. Trajetórias das análises de risco: da periferia ao centro da teoria social. Revista Brasileira de Informação Bibliográfica em Ciências Sociais (BIB), v. 46, n. 2, p. 3-38, 1998.

Sustentabilidade e métodos participativos: os riscos dos pressupostos realistas. ENANPPAS - ENCONTRO ASSOCIAÇÃO NACIONAL DE PÓS-GRADUAÇÃO E PESQUISA EM AMBIENTE E SOCIEDADE, 1., 2002. Indaiatuba/SP. Anais.

GUIMARÃES, N. A.; MARTIN, S. (Org.). Competitividade e desenvolvimento: atores e instituições locais. São Paulo: Senac, 2001.

HOGAN, D.; MARANDOLA Jr., E. J. (Orgs.). População e mudança climática: dimensões humanas das mudanças ambientais globais. Campinas: Núcleo de Estudos de População (NEPO/Unicamp). Brasília: UNFPA, p. 29-52, 2009.

HOGAN; D. J. et al. Urbanização e vulnerabilidade socioambiental: o caso de Campinas. In: et al. (Orgs.). Migração e ambiente nas aglomerações urbanas. Campinas: MPC Artes Gráficas, 2001. p. 397-418.

IBGE - Instituto Brasileiro de Geografia e Estatística. Dados do Censo Demográfico de 2007. Disponível em: <http://www. ibge.gov.br/home/>.

IPCC - Intergovernmental Panelon Climate Change. Working Group II - Climate Change Impacts, Adaptation and Vulnerability. Crown: United Kingdom, 2007.

JASANOFF, S.; MARTELLO, M. L. (Eds.). Earthly politics: local and global in Environmental Governance. Boston: MIT Press, 2004. p. 335-350.

KASPERSON, R. E.; PALMLUND, I. Evaluating Risk Communication. In: ; KASPERSON, J. X. (Ed.). The Social Contours of Risk: publics, risk communication and the social amplification of risk. London: Earthscan, 2005.
KRON, W. Coasts - The riskiest places on Earth. In: SMITH, J. M. (Org.). Coastal Engineering. In: INTERNATIONAL CONFERENCE ON COASTAL ENGINEERING (ICCE, 2008), 31., 2008. Hamburg, Germany. Proceedings.

KRUEGER, R. A. Focus groups: A practical guide for applied research. Sage Publications. 1994.

MARICATO, E. Metrópole na periferia do capitalismo: ilegalidade, desigualdade e violência. São Paulo: Hucitec, 1996.

McGRANAHAN, G.; BALK, D.; ANDERSON, B. The rising tide: assessing the risks of climate change and human settlements in low elevation coastal zones. Environment and Urbanization, v. 19, n. 1, p. 17-37, 2007.

MORGAN, D. L. Focus groups as qualitative research. London: Sage Publications, 1988.

. Planning focus groups. London: Sage Publications, 1998.

OWENS, S. Engaging the public: information and deliberation in environmental policy. Environment and Planning A, v. 32, p. 1141-1148, 2000.

PARKER, S.; SPIRES, P.; FAROOK. F.; MEAN, M. State of trust: How to build better relationships between councils and the public. London: DEMOS, 2008.

RENN, O. Risk governance: coping with uncertainty in a complex world. London: Earthscan, 2008.

; LEVINE, D. Credibility and trust in risk communication. In: KASPERSON, R. E.; SLATLEN, P. J. M. Communicating risks to the public: international perspectives. Netherlands: Kluwer Academic Publishers, 1991. p. 175-218.

VIGLIO, J. E. Usos sociais e políticos da ciência na definição de riscos e impactos ambientais no setor de petróleo e gás. Campinas, Tese (Doutorado em Ciências Sociais) - IFCH-UNICAMP, 2012.

WILSDOM, J.; WYNNE, B.; STILGOE, J. The public value of science: or how to ensure that science really matters. 2005. London: Demos, Magdalen House. Disponível em: $<$ http:// www.demos.co.uk/files/publicvalueofscience.pdf $>$. Acesso em: 07/11/2008.

Recebido em 10 de dezembro de 2012. Aceito em 11 de outubro de 2013. Publicado em dezembro de 2013. 